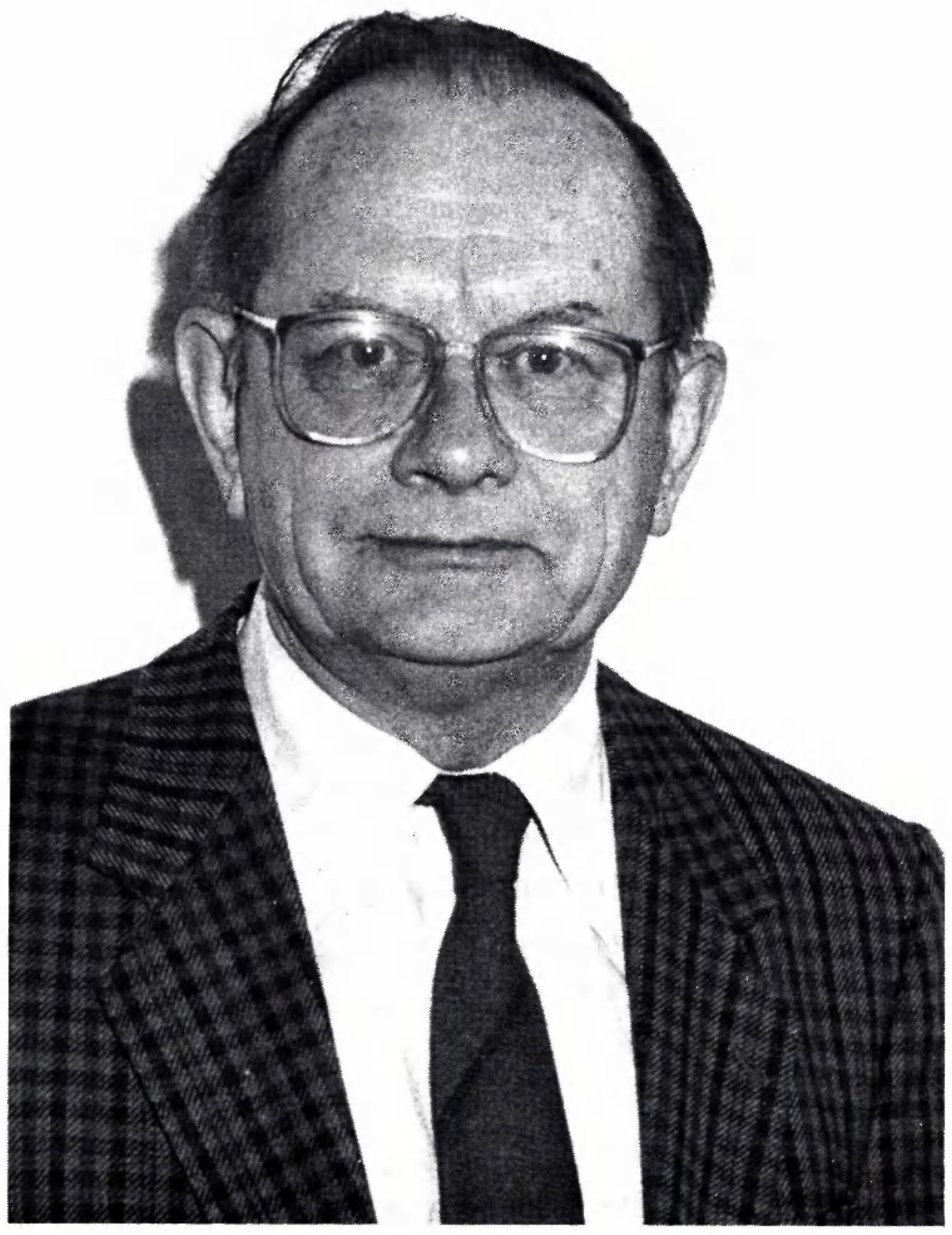

Photograph: Piet Jansen 


\section{About Professor G. H. Bolt}

Gerard Hendrik Bolt was born in April 1925 in Arnhem, Netherlands, where he attended primary and secondary schools. In 1942 he obtained in his birth-town the diploma of the HBS, the 'hogereburgerschool'. In September of the same year he started his studies at the Wageningen Agricultural University. However, German occupation of the Netherlands during World War II forced him to break off his study already in the spring of 1943.

He proceeded his education at the State University College of Tropical Agriculture in Deventer where he obtained his B.Sc. degree in 1945, shortly after the liberation of the Netherlands.

Then he resumed his studies in Wageningen where he was awarded the degree of 'Landbouwkundig Ingenieur' in drainage engineering in 1950, with majors in drainage and agricultural chemistry, and minors in physics and agrogeology.

During his studies in Wageningen he became an assistant at the Agricultural Chemistry Laboratory of the University. In that period the basis was laid for a friendship with the man he considered as an important teacher in his early scientific education, the late Professor A. C. Schuffelen. With Schuffelen he would later closely cooperate for a number of years.

The 4th International Congress of Soil Science held in Amsterdam (1950), where the late Professor C. H. Edelman was chairing the organizing committee, was an important event, also for Bolt personally. At that occasion he was offered an assistantship in the Agronomy Department at Cornell University, Ithaca, New York. This enabled him to start studying at that University. Here he obtained a M.Sc. degree in soil chemistry in June 1952 on a thesis entitled 'The significance of the measurements of the zeta potential and the membrane potential in soil and clay water systems'.

He continued his study at Cornell University where he was awarded a Ph.D. degree in soil physics in the summer of 1954 on the thesis 'Physico-chemical properties of the electric double layer on planar surfaces'. This part of his scientific career was guided by R. D. Miller and M. Peech, both connected with the Agronomy Department of Cornell University. In terms of Ph.D. heritage lines in soil science, he thus became a 'grand-grand-son' of L. A. Richards, of whom R. D. Miller is a grandson through M. B. Russell. While being at Cornell his basic approach of soil chemistry problems was strongly influenced during many discussions with R. K. Schofield, who was spending his sabbatical there.

After finishing his studies, he took a position as research associate with the Agronomy Department of Cornell University for about one year, in the meantime serving as a consultant on a research project on electro-osmotic stabilization of soil at the Soil Mechanics Department of Harvard University. Then he moved to Dupont Experimental Station in Wilmington, Delaware, where he acted as a research chemist. 
In 1957 he returned to Wageningen Agricultural University where he was appointed as Reader in soil science at the Agricultural Chemistry Laboratory, which was then headed by Schuffelen. In 1963 he obtained his appointment as Professor of soil physics and soil chemistry, in which position he has served his Alma Mater until his present retirement.

As became already apparent in his early scientific work, Bolt had a profound interest in both the chemical and the physical aspects of soil science. This is clearly reflected in his own research papers, as it is in the work of the students he guided in the preparation of their doctoral theses. The subjects he covered in his own M.Sc. and $\mathrm{Ph}$.D. theses remained, understandably, of special interest to him. While being at Dupont he focussed on titration of oxides, a topic which is still of great importance especially in relation to acid deposition.

Back in Wageningen he spent much effort in the development of educational programmes in soil science and acquired a reputation of an outstanding teacher and lecturer. Because he considered teaching of students as his first and major task, substantial attention was given to the collection and writing of course material. These activities culminated in two textbooks on soil chemistry, with emphasis on basic elements and physico-chemical models, respectively. Strongly encouraged by Bolt, his co-workers took care of the appearance of a comparable basic textbook on soil physics, based on earlier lecture notes by Bolt.

Also the organizational aspects of establishment and re-adjustment of teaching programmes obtained his lasting interest. There has been a time when the 're-programming Bolt' was a common term at the Wageningen University. He served in many Dutch committees related to university educational and research programmes, of which are mentioned:

- 1959-1961: secretary of the committee on fundamental research in agriculture;

- 1962-1965: secretary of the committee on statutory change of Wageningen Agricultural University;

- 1963-1967: member of the committee of the Netherlands Academic Council on Education and Teaching;

- 1967-1969: chairman of a committee on education and teaching of Wageningen Agricultural University;

- 1972-1974 and 1982-1984: member of the Faculty Council of Wageningen Agricultural University;

- 1976-1982: secretary of the Board of Deans of Wageningen Agricultural University;

- 1974-1984: member of the Netherlands America Commission on Educational Exchange.

- 1985- : member of the Advisory Committee of the State University College of Tropical Agriculture in Deventer.

- 1986- : member of the Netherlands Council for Education.

- 1986- : member of the Netherlands Council for Environmental and Nature Research.

Since 1968, Bolt is a Fellow of the Soil Science Society of America. He served from 1964-1968 as President of Commission I (Soil Physics) of the International Soil 
Science Society. He was a Fulbright Scholar at the University of California in Riverside in 1964, and Pye Fellow with CSIRO in Canberra, Australia, in 1970. In the spring of 1975 he acted as a consultant for UNESCO/UNDP at the Hissar project, India, and he was visiting professor at Technion, Haifa, Israel in 1979. At the International Soil Science Congress in Hamburg, in 1986, he was elected President of Commission II (Soil Chemistry) of the ISSS for the period 1986-1990.

While Bolt's personal work was greatly contributing to the development of theories applied in soil science, the research work performed and described by his doctoral students offered an additional opportunity to direct the attention towards specific problems and possible ways to solve them. It is beyond any doubt that his intensive and pervasive scientific discussions on the way of thesis preparation have considerably improved the final results.

Bolt's personal contributions to the scientific literature in soil science have been presented in some hundred scientific papers, which are listed elsewhere in this issue. The variation of subjects treated by his doctoral students is shown in the below chronological summarized descriptions.

In 1965, F. A. M. de Haan wrote a thesis entitled 'The interaction of certain inorganic anions with clays and soils'. This work focussed on the simultaneously occurring processes of adsorption and exclusion of anions at soil colloids. In soil systems both processes usually have to be taken into consideration because they are of comparable order of magnitude. Hence a correct interpretation of adsorption of anions of practical importance such as phosphate requires information about anion exclusion phenomena. Moreover, anion exclusion measurements may provide a good means for the determination of the specific surface area of predominantly negatively charged soil constituents.

P. H. Groenevelt obtained his Ph.D. in 1969 on the thesis 'Coupling phenomena with transport processes in soil' (in Dutch), which described the interdependency of transport processes occurring in the liquid phase of a porous system containing a stable solid phase. By applying the theory of 'thermodynamics of irreversible processes' a system of transport equations was derived which could take care of all possibly occurring fluxes. Different relevant transport coefficients were calculated by model approach. Experimental verification was obtained by application of a nondestructive method for the determination of moisture contents in soil columns with the use of weak $\gamma$-radiation.

In 1970, P. Reiniger was awarded a Ph.D. degree at the Hebrew University, Jerusalem, Israel, on the thesis 'Movement and exchange of sodium and calcium in calcareous and gypseous soils'. Bolt acted as co-promoter, together with Professor D. H. Yaalon. Reiniger departed from the theory of chromatography in order to describe the displacement of $\mathrm{Na}$ and $\mathrm{Ca}$ in soil systems, taking different forms of ion exchange into account, viz unfavourable, favourable, and linear isotherms. Results of computer model calculations were verified by translocation experiments in soil columns.

M. Leistra wrote his thesis 'Diffusion and adsorption of the nematicide 1,3-dichloropropene in soil' in 1972, focussing on the distribution of the cis- and transform of the nematicidal compound indicated after soil fumigation. Also distribution 
coefficients of the compounds over different soil phases at varying conditions were measured. Computation models were applied in order to calculate dose patterns in soil under various circumstances. Estimates for the relative importance of different ways of disappearance from the soil system, viz volatilization, leaching, and decomposition, were included.

Also in 1972, M. G. M. Bruggenwert was awarded a Ph.D. degree on the study 'Adsorption of Al-ions on the clay mineral montmorillonite' (in Dutch). It was found that the adsorption isotherms of $\mathrm{Al}^{3+}$ and $\mathrm{La}^{3+}$ on montmorillonite were fairly similar, as were these isotherms for the adsorption of the same compounds on resin. This allowed the conclusion that adsorptive behaviour of $\mathrm{Al}^{3+}$ for montmorillonite was governed by electrostatic properties and not by specific properties of aluminium or montmorillonite. Contradictions as found in literature on the hydrolysis of aluminium ions in the presence of clay minerals could be resolved by a hypothesis based on the theoretical considerations involved in this study.

$\mathrm{J}$. Hoeks wrote the thesis 'Effect of leaching natural gas on soil and vegetation in urban areas', again in 1972. Use of existing gas distribution systems for regional distribution of natural gas introduced many leakage problems with profound effects on physical, chemical and biological processes in soil. Microbial oxidation of methane takes a key position in this respect. Distributions of gaseous compounds in soil near leakages were performed with computation models, and experimentally verified. Analysis of the importance of different system parameters allowed the development of measures in order to improve soil conditions after leak repair, or to be applied in a preventive way.

In 1974, Raj Pal obtained a Ph.D. at the Haryana Agricultural University, Hissar, India, on the thesis 'Transport and accumulation of ions in soil' for which Bolt acted as major supervisor, together with Professor S. S. Khanna. Various solutions were percolated through columns of carborundum, resin and gypsum. Theoretical breakthrough curves were derived on the basis of solute transport in combination with ion adsorption, and compared with experimental breakthrough. This allowed the calculation of distribution exchange coefficients. Good agreement was found between the dispersion coefficients as calculated from the experimental and theoretical chloride breakthrough curves, and the numerical dispersion coefficients derived from calculations.

L. Stroosnijder wrote in 1976 the thesis 'Infiltration and redistribution of water in soils' (in Dutch). Three different ways were compared for the prediction of infiltration for irrigation of a basin, viz a numerical, a semi-analytical, and an analytical approach. It was concluded that complex models for water redistribution were of little value in practice since they could not be generalized and required too many physical soil data. Also a scheme was developed that grouped techniques for estimating physical properties of soil, according to cost and required expertise.

K. Harmsen studied the 'Behaviour of heavy metals in soils' and wrote a Ph.D. thesis with this title in 1977. Soil samples were collected near zinc smelters, on a sewage farm, and along a river formerly discharging heavy metals. Different extraction procedures were applied to obtain information on bonding mechanisms of heavy metals in soils, with emphasis on the role of oxides of Fe and $\mathrm{Mn}$. The role of 
hydrolysis and adsorption of hydrolysis products was studied. Ion exchange was described in terms of sites of high and low selectivity. A distinction was made between regular and specific exchange adsorption and superequivalent adsorption. The lowering of $\mathrm{pH}$ upon heavy metal adsorption could be ascribed to desorption of weakly acidic protons or adsorption of hydrolysis products.

'Phosphate retention by soil in relation to waste disposal' was the thesis of J. Beek in 1979. A model was developed in order to describe the movement of phosphate through soil systems. Extensive field data were collected on a sewage farm on which domestic sewage water had been disposed during about half a century. Aluminium and iron being the main soil constituents in phosphate bonding, considerable attention was given to extraction procedures in order to characterize their active fractions in soil. Also the kinetic aspects of phosphate bonding were studied. The reliability of the model as developed with respect to long-term predictions, was checked by using sewage farm data. A good agreement was found between predicted and measured distributions.

For the thesis of R. Brinkman, in 1979, entitled 'Ferrolysis, a soil-forming process in hydromorphic conditions', Bolt acted as co-promotor, together with Professor L. J. Pons. Ferrolysis stands for the process in which decomposition and interlayering of clay occurs in acid, seasonally wet soils under the influence of rhythmic reduction and oxidation of iron. The implications of this process were tested by morphological, chemical and mineralogical analysis of a number of soils from south-east Asia and different parts of Europe. Until then, ferrolysis was not clearly distinguished from cheluvation, clay translocation, and desilication. Criteria were developed to differentiate between the effects of these processes.

In 1986, Bolt and Professor L. Wartena were promotors, with Dr L. Stroosnijder as co-promotor, for H. F. M. ten Berge on his study 'Heat and water transfer at the bare soil surface; aspects affecting thermal imagery'. The sensitivity of surface temperature and surface energy fluxes was studied by means of numerical simulation incorporating coupled heat and moisture transfer, both in soil and atmosphere. Such a model is an instrument to link the fields of boundary layer meteorology and soil physics, an essential step to a better understanding of surface processes. Along with simulation, both the behaviour of topsoil moisture and temperature were studied in several field experiments. The possibilities to assess bare soil conditions and surface fluxes by means of thermal infrared remote sensing appeared to be very limited.

Also in 1986, J. J. T. I. Boesten finished his doctoral study, with Dr M. Leistra as co-promotor, with the thesis 'Behaviour of herbicides in soil: simulation and experimental assessment'. A simulation model was developed of the transport of herbicides in soil under field conditions, based on the best model available in literature. Detailed field experiments were carried out on a bare loamy soil with two soil-applied herbicides in order to test the model. Testing the herbicide transport model against concentration profiles measured in the field showed considerable discrepancies. Sorption of the herbicides was studied in detail in laboratory experiments, resulting in a new model for sorption which was then incorporated into the transport model. The new model successfully explained the field measurements. 
In preparation are theses by:

P. A. Leffelaar on 'Dynamics of partial anaerobiosis, denitrification and water in soil: experiments and simulation' (with Bolt as co-promotor along with Professor C. T. de Wit);

P. Keizer on 'Behaviour of heavy metal ions in a clay-aluminium-hydroxide system' (with Dr M. G. M. Bruggenwert as co-promotor);

T. Hiemstra on 'Aspects of soil acidity' (with Dr M. G. M. Bruggenwert as co-promotor).

Unfortunately, many people still associate soil chemistry and soil physics with "theoretical sophistication'. While looking at the variety of applied agricultural research fields in which Bolt's former doctoral students are currently working, this view is evidently unjustified. The above research fields apparently stand out as central and indispensable to the study of many contemporary soil problems, both in industrialized and in developing countries.

With the increasing and ongoing specializations in the different fields of soil science, it became a unique situation that the two so comprehensive areas 'soil chemistry' and 'soil physics' were united in one person. It may be considered as typical for Bolt's broad interests, enthousiasm, and zest for work that he succeeded to cover both subject areas until the end of his professional career.

Frans A. M. de Haan and Hein F. M. ten Berge 